\title{
Knowledge and Perception of Child Autism Among Preschool Teachers in the Ledzokuku-Krowor Municipal Assembly, Ghana
}

\author{
Alberta Twi-Yeboah ${ }^{1}$, Abdul Cadri ${ }^{1,2, ~ *, ~ B o n y o ~ A b d u l ~ A z i z ~ N a g u m s i ~}{ }^{3}$, Nana Ama Asi Danso ${ }^{4}$, \\ Nadia Mohammed-Sani ${ }^{5}$ \\ ${ }^{1}$ Social and Behavioural Science, School of Public Health, College of Health Sciences, University of Ghana - Legon, Accra, Ghana \\ ${ }^{2}$ Department of Family Medicine, Faculty of Medicine, McGill University, Montreal, Quebec, Canada \\ ${ }^{3}$ Health Policy, Planning and Management, School of Public Health, College of Health Sciences, University of Ghana - Legon, Accra, Ghana \\ ${ }^{4}$ Population, Family and Reproductive Health, School of Public Health, College of Health Sciences, University of Ghana - Legon, Accra, \\ Ghana \\ ${ }^{5}$ Faculty of Health Sciences, Presbyterian University College, Abetifi, Eastern Region, Ghana
}

\section{Email address:}

atwiyeboah@yahoo.com (A. Twi-Yeboah), abdul20c@yahoo.com (A. Cadri), meetaziz11@gmail.com (B. A. A. Nagumsi), nanamadanso@gmail.com (N. A. A. Danso), nadiamohammedsani@gmail.com (N. Mohammed-Sani)

${ }^{*}$ Corresponding author

\section{To cite this article:}

Alberta Twi-Yeboah, Abdul Cadri, Bonyo Abdul Aziz Nagumsi, Nana Ama Asi Danso, Nadia Mohammed-Sani. Knowledge and Perception of Child Autism Among Preschool Teachers in the Ledzokuku-Krowor Municipal Assembly, Ghana. Central African Journal of Public Health. Vol. 7, No. 2, 2021, pp. 65-75. doi: 10.11648/j.cajph.20210702.14

Received: March 22, 2021; Accepted: April 6, 2021; Published: April 20, 2021

\begin{abstract}
Background: Autism is increasing worldwide; however, preschool teachers, who are the primary caregivers beside parents in most situations are not able to accurately detect the symptoms of autism to respond appropriately as this is of utmost importance to help provide early healthcare to autistic children. The study assessed the knowledge and perception of preschool teachers towards child autism in the Ledzokuku-Krowor Municipality. Methods: A total of 210 preschool teachers (58\% females) in 8 selected communities in the Ledzokuku Krowor Municipal Assembly, Ghana completed questionnaires relating to their demographic characteristics, level of knowledge in typical child development, child autism, perceptions and attitudes. A cross-sectional study design was employed using a quantitative technique. The association between dependent and independent variables and were examined using univariate and multivariable analyses. Statistical significance was set at $\mathrm{p}<0.05$ and analysis was performed with Stata Version 15. Results: The findings of the study revealed that preschool teachers had low levels of knowledge in ASD. The results also showed that preschool teachers had positive attitudes and perceptions towards education of children with autism. Finally, there was a significant association between knowledge of ASD and, attitudes and perceptions towards ASD $(\mathrm{p}<0.05)$. Conclusion: Preschool teachers generally possess low levels of knowledge about autism spectrum disorder. Even though preschool teachers have positive attitudes and perceptions towards the provision of education for autistic children, increasing their knowledge will result in a more positive attitude and perception towards other needs of autism spectrum disorder and also help in early detection of autism.
\end{abstract}

Keywords: Autism, Knowledge, Attitude, Perception, Pre-school, Teachers

\section{Background}

American Psychiatric Association (APA) explains Autism Spectrum Disorder (ASD) to be a range of neurobehavioral disorders that occurs a few years after a child is born. This condition is mostly identified with difficulty in communication and relational connection, as well as repeated patterns of doing things, among others [1]. The most common and easiest ways to identify autistic children are the presence of some traits such as difficulty in understanding 
simple issues and instructions, unresolved influences, poor social interactions and connection, social confinement, and adjustment issues [2-4]. Some autistic children also show very aggressive behavior, some act in a reckless manner, and others show unacceptable forms of behavior or a combination of all [5-7].

Autism Spectrum Disorder is gaining attention and increasing in scope, in terms of prevalence [8]. The prevalence of autism, as a study reported ranges from 13.1 per 1000 children in Colorado to 31.4 in New Jersey [9]. The World Health Organization has indicated that ASD is becoming far more prevalent in some low-and middleincome countries than was anticipated which is contrary to the previous findings by a study that reported that ASD is more prevalent in the West and not in children from Africa [10]. Autism Spectrum Disorder is usually accompanied by other comorbid conditions like epilepsy, anxiety, intellectual disability, etc. [7, 11-13]

It has been reported that some characteristic features common in ASD in Africa include: intellectual disability, extreme speech delays, and late identification; that is identification after age 8 [14]. The ability to diagnose autism at a much younger age plays a relevant role in choosing what treatment option will yield the desired outcome for an autistic child [15]. This implies that poor awareness of ASD could result in poor recognition of interventions or a lack of these interventions. Moreover, a lack of awareness could also contribute to delays in seeking help and could be attributed to families of children with autism experiencing a high degree of stigma.

Based on a study carried out in China, a middle-income country with very similar and low prevalence estimates (i.e., $0.11 \%$ ) like Ghana, it was observed that the general population shows inaccurate recognition of the etiology and intervention options available for the disorder. A study reported that there is gap in knowledge on autism among a Malaysian population [16]. A low level of knowledge of ASD is known to increase the burden of families with an autistic child, contributes to the stigma, and may impede epidemiological efforts [13, 17-19]. A study on the knowledge and perception of ASD among school teachers in Karachi, Pakistan reported that $55 \%$ of teachers had heard about autism [20]. Another study conducted in China revealed that the majority of participants (84\%) accurately answered over $50 \%$ of the items evaluating their understanding of normal childhood development as against 83 percent incorrectly answering to more than half of the questionnaire items evaluating ASD knowledge [21].

Findings from a study indicated that the majority of the respondents who knew about autism confirmed they wouldn't move away or be scared if an autistic person sat next to them in the bus compared to those who were ignorant of the condition [22]. Individuals who do not comprehend autistic children frequently see them as selfish, slow, and strange [16]. Findings of the research indicated that individuals still associate the cause of autism with supernatural forces [23].

Most children are enrolled in pre-schools at a very tender age mostly due to the high demands of their parents' jobs. This situation makes preschool teachers second to parents to contribute to the child's development. Their lack of knowledge and misconceptions of the condition hinders the likelihood of early identification and intervention for these children. This can make verbal interventions unrealizable and could largely account for the many non-verbal cases found in Africa [23-25].

Despite the relevance of knowledge on ASD among preschool teachers, there is limited literature on the topic among preschool teachers in Ghana. This study therefore aimed at determining the level of knowledge of preschool teachers on Autism, assess their attitudes and perceptions towards education for Autistic children, and lastly, determine the effect of knowledge on attitudes and perceptions of preschool teachers. Findings from this study would help bridge the gap in knowledge on autism among preschool teachers in Ghana. The findings will also expand information and awareness of ASD which will improve early identification and diagnosis. This improvement will result in a good prognosis, as well as early childhood interventions. This study will also inform policies and interventions that will be beneficial to practice in the country. Moreover, given that the Sustainable Development Goal 4 is geared towards inclusive and equitable quality education and promotion of lifelong learning opportunities for all [40], findings from this study would contribute to the achievement of goal 4 concerning inclusive and equitable quality education for autistic children.

\section{Methods}

\subsection{Study Area}

This research was conducted in the Ledzokuku-Krowor Municipality (Lekma) in the Greater Accra Region of Ghana. Lekma's complete land area is estimated at 50 square kilometers. The municipality's population is about 227,932. A total of 214 registered pre-schools exists in the municipality with a staff strength of 535 spread across the various zonal communities which is made up of 31 public pre-schools and 183 private pre-schools. There are 124 teachers in public preschools and $106(90.8 \%)$ of them are trained teachers. There are 411 teachers in private kindergartens and $63(5.3 \%)$ of them are trained teachers [26].

\subsection{Study Design}

The study was a cross-sectional study involving teachers in private and public pre-schools. It was conducted from February to May 2019.

\subsection{Study Population}

Participants for this study were all preschool teachers in the Ledzokuku-Krowor Municipality with at least one year of preschool teaching experience. All preschool teachers who met the inclusion criteria but were absent on the day of the data collection, as well as those who refused to voluntarily take part in the study were excluded. 


\subsection{Study Variables}

\subsubsection{Dependent Variables}

The primary outcome variable for the study was the level of knowledge of preschool teachers on child autism while the participant's attitude and perceptions towards child autism was the second dependent variable.

\subsubsection{Independent Variables}

The independent variables considered were the background characteristics of the participants measured in the study. These variables comprised of their age, years of working, sex, type of school, marital status, whether they have a child or not, level of education, their previous experience with an autistic child, and whether they have received some training on early childhood education and special-needs disorders or not.

\subsection{Sample Size Determination}

The sample size required for this study was estimated by using the Cochrane formula for determining proportions. A proportion of $17 \%$ of teachers well knowledgeable with ASD was taken from a related study [21]. With a level of precision set at 5\% and 95\% level of confidence, a total sample of 217 were recruited for the study.

\subsection{Sampling Technique}

This study employed a multi-stage sampling approach to achieve its objectives. Stratified, systematic, and simple random sampling methods were employed in this multi-stage sampling. In the first stage, since the municipality had already been stratified into four classes based on socioeconomic status, two communities were randomly selected from each stratum. Systematic sampling was then used to select public and private preschools in the communities. Sample units from pre-schools were selected using the simple random sampling method (Yes or No).

\subsection{Data Collection Instruments and Methods}

Data for the study were collected with an adopted questionnaire from a previous study [21]. The questionnaires were self-administered since the target group which was teachers were a learned class. The questionnaire comprised five sections; section A had questions that measured participants' background characteristics while sections B, C, $\mathrm{D}$, and E measured participants' knowledge on normal child development, as well as child autism, attitude and perceptions, and awareness on autism-friendly centers in Ghana. The questionnaire assessing knowledge, attitude, and perception of ASD and the awareness of autism-friendly centers was adopted from previous research [21, 27] intended for this purpose.

\subsubsection{Knowledge Level}

This section comprised 32 True/False questions with two domains. The first domain contained 15 items that focused on measuring participants' knowledge of typical child development [27] whiles the last 17 items were targeted at assessing participants' knowledge on ASD [21, 27]. Each correctly answered question was awarded a score of 1 while "don't know" and wrong answers were given a score of zero. The level of knowledge of the respondents in these areas was obtained by summing all the item scores to generate the total scores for the two aspects of knowledge. The scores ranged from 0 to 14 points for the knowledge on the domain of typical child development and 0 to 15 for the domain for knowledge on ASD (except for the last two items, one repeated question, and the last question which served as a predictive validity question). For knowledge on typical child development, participants who scored 7 and below were categorized as low level of knowledge on typical child development while those that scored 8 and above were categorized as high level of knowledge on typical child development. Similarly, for knowledge on ASD, participants with a score level of 7 and below were categorized as low level of knowledge whereas those with a score of 8 and above as high level of knowledge on ASD. Further adopting the procedure used by previous researchers, respondents were categorized as "Pass" if correctly answered more than half of the questions per each domain $(>50 \%)$.

\subsubsection{Attitude and Perceptions}

This aspect of the questionnaire comprised of nine Likert items measured on a scale of 1 to 5 (1- Strongly Disagree, 2Disagree, 3- Neutral, 4- Agree 5- Strongly Agree). The nineitem questionnaire assessing attitudes and perceptions was adopted from a previous survey [27]. The questions were assessing the attitudes concerning entitlements for children with ASD (e.g., 'Preschools should have teachers with special education and therapists who would provide services for children with special needs, etc.). The average of the responses on the Likert-style scale was found for each questionnaire item.

\subsection{Data Processing and Analysis}

The data was entered using the code assigned to each response into Statistical Package for Social Science. Consistency checks and data cleaning were done and exported into STATA (Version 15) for data analysis. ShapiroWilk, skewness, and kurtosis tests for normality were used to assess the normality of continuous data. The reliability of the various scales in the questionnaire was ascertained with the Cronbach's alpha test statistic.

Descriptive statistics for categorical variables were presented in the form of frequencies and percentages as well as pie charts. Continuous variables were reported in terms of averages and standard deviations or median, based on the distribution of the data. A linear regression model was used to identify the factors that were associated with participants' knowledge of ASD, as well as their attitudes and perceptions.

\subsection{Ethical Approval and Consent to Participate}

Ethical approval was sought from the Ghana Health Service Ethics Review Board (GHS-ERC052/02/19/). Permission was also sought from the Lekma Ghana 
Education Service. The approval from the Ghana Education Service- Lekma together with the ethical approval from the Ghana Health service were submitted to heads of schools to seek their permission before data collection started. Informed consent forms together with information sheets were first administered to study participants and participants were assured of their anonymity and confidentiality.

\subsection{Quality Control}

The questionnaire was pretested in three selected schools among 24 participants in Nungua, one of the communities in Lekma. After this, all issues with the wording of the questions as well as questions that were ambiguous and difficult to understand were changed or replaced before it was used for the main survey. In both pretest and main survey, filled questionnaires were double-checked by the researcher and two field research assistants to identify non-responses to questions and all deviations were corrected instantly. After all inconsistencies had been checked and corrected, the data were entered after each day's activity.

Table 1. Characteristics of Study Participants.

\begin{tabular}{|c|c|c|}
\hline Characteristics & Frequency & Percentage $\%$ \\
\hline \multicolumn{3}{|l|}{ Age of respondent } \\
\hline$<28$ & 66 & 31.0 \\
\hline $28-36$ & 73 & 34.3 \\
\hline$>37$ & 71 & 33.3 \\
\hline \multicolumn{3}{|l|}{ Sex of respondent } \\
\hline Male & 87 & 40.8 \\
\hline Female & 123 & 57.7 \\
\hline \multicolumn{3}{|l|}{ School type } \\
\hline Public & 44 & 20.7 \\
\hline Private & 166 & 77.9 \\
\hline \multicolumn{3}{|l|}{ Marital Status } \\
\hline Married & 96 & 45.1 \\
\hline Unmarried & 114 & 53.5 \\
\hline \multicolumn{3}{|l|}{ Has a child } \\
\hline Yes & 113 & 53.1 \\
\hline No & 97 & 45.5 \\
\hline \multicolumn{3}{|l|}{ Level of Education } \\
\hline WASSCE/SSCE & 124 & 58.2 \\
\hline Diploma/HND & 66 & 31.0 \\
\hline Bachelor's Degree & 18 & 8.5 \\
\hline Masters & 2 & 0.9 \\
\hline \multicolumn{3}{|l|}{ Teaching Experience } \\
\hline $1-4$ years & 71 & 33.3 \\
\hline 5-9 years & 71 & 33.3 \\
\hline$>=10$ years & 68 & 31.9 \\
\hline \multicolumn{3}{|l|}{ Training in childhood development } \\
\hline Yes & 126 & 59.2 \\
\hline No & 84 & 39.4 \\
\hline \multicolumn{3}{|l|}{ Training in special-needs disorder } \\
\hline Yes & 130 & 61.0 \\
\hline No & 80 & 39.0 \\
\hline \multicolumn{3}{|l|}{ Experience with a special-needs child } \\
\hline No previous experience & 55 & 25.8 \\
\hline Previous experience & 65 & 30.5 \\
\hline Child in the present class & 90 & 42.3 \\
\hline Community Socio-economic class & 78 & 37.1 \\
\hline Residential First class & 10 & 31.1 \\
\hline Residential second class & 87 & 41.4 \\
\hline Residential Third class & 45 & 21.4 \\
\hline
\end{tabular}

\section{Results}

\subsection{Characteristics of Participants}

The majority of the participants were females, 123 (57.7\%). More than half, 114 (53.5\%) of the participants reported they were unmarried, whereas $53 \%$ reported that they had a child/children. The average age of teachers was 33.91 with a minimum age of 18 and a maximum age of 65 . Teachers generally had an average of 7.70 years of experience teaching as a preschool teacher. The majority of the respondents, 126 $(59.2 \%)$ indicated that they had received some training in early childhood development, likewise training in specialneeds disorders, $130(61 \%)$. Also, more than $70 \%$ of all participants stated that they had a previous/current working experience with a special-needs child. Table 1 shows a summary of the background characteristics of the participants.

\subsection{Knowledge About Typical Child Development}

The results of the categorization of the knowledge score of 
preschool teachers showed that the majority of them, 129 (61.4\%) had a low level of knowledge on typical child development whereas the remaining $81(38.6 \%)$ presented a high level of knowledge (figure 1).

Further analysis of the individual items on the subscale showed that more than half of the participants identified correctly that it is true for a 3-year-old child to alternate between play games (57\%). They also suggested accurately that, a 5-year-old should be able to engage in conversations about activities in the day $(66 \%)$. The majority of the participants $(53.6 \%)$ were also able to correctly identify that, 'An inattentive child may be having seizures. About 51\% were able to identify that it was not normal for a child at 3 years to frequently mouth objects. An average of $57 \%$ of participants also correctly answered that "A child should participate meaningfully during Music and Movement". Finally, 54\% of participants answered correctly that, "A child with poor language skills can appear hyperactive and inattentive in class" likewise that, "most children are slightly hyperactive and inattentive before the age of $5 "$. The results of participants on domain on typical child development are presented in table 2 .

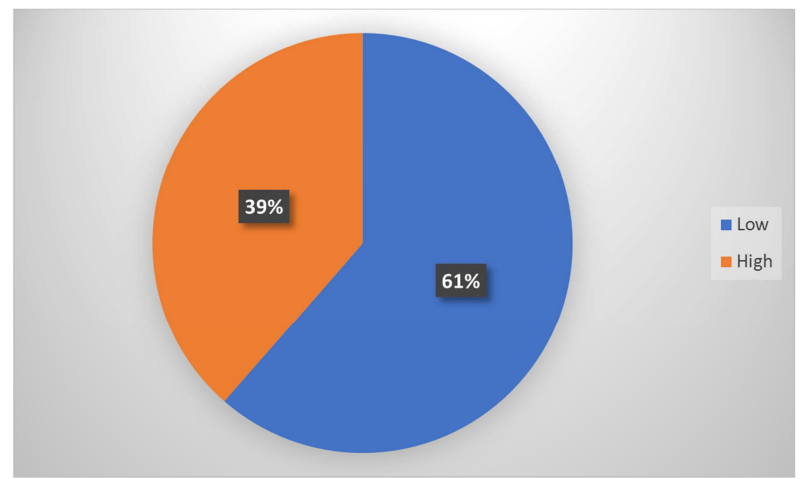

Figure 1. Level of knowledge of teachers on typical child development.

Table 2. Knowledge of typical child development questionnaire items passed by $<50 \%$ of respondents.

\begin{tabular}{lll}
\hline Question & Correct Response \\
\hline 1. A child at 3 can still be unsteady when walking. & False \\
2. A year and a half old should have hand dominance. & False \\
3. A child can only stage play at 4 years old. & False \\
$\begin{array}{l}\text { 4. 3-year-old child should alternate between games to play } \\
\text { 5. 5-year-old should be able to engage in conversations. }\end{array}$ & True & True \\
6. Inattentive child may be having seizure. & True & False \\
7. A 3-year-old should not understand simple instructions. & False \\
8. It is normal for a boy to start speaking at the age of 2. & False \\
9. At 3 years a child should still be mouthing objects. & True \\
10. A child should participate during Music and Movement. & False \\
11. 3-year-old should be able to recognize things but unable to speak. & True \\
12. Most children are hyperactive and inattentive before 5. & True \\
13. A child with poor language skills can appear hyperactive. & True \\
14. Family problems can lead to child learning and behavioural problems. & $53.59(49.9-63.7)$ \\
\hline
\end{tabular}

Note: CI-confidence interval

\subsection{Knowledge About Autism}

The results of the categorization of the knowledge score of preschool teachers on ASD showed that only 45 (21.4\%) of the teachers had a high level of knowledge on childhood ASD. The majority of them, $165(78.6 \%)$ had a low level of knowledge on childhood ASD (figure 2).

The analysis of the individual items of the subscale showed that, except for three questions that more than half of participants answered correctly, less than half of the participants were unable to answer correctly to the rest of the questions on the knowledge of child autism. Some of the inconsistencies identified in participants' responses included: most of the preschool teachers were of the impression that autistic children are deliberately negativistic and noncompliant. Most participants also believed that autism may be caused by poor parenting. Most teachers also shared the view that autism occurs more commonly among children born to parents in the higher socio-economic bracket. However, the majority $(75.2 \%)$ were able to correctly identify that; child autism often exhibits features of speech and language delay between ages 2 and 3. Likewise, the majority $(59.5 \%)$ of them identified accurately that autism presents in repetitive behavior and that it is important that special education services are provided for autistic children at school (63.81\%). Table 3 presents the knowledge performance of participants in the domain of Autistic spectrum disorder.

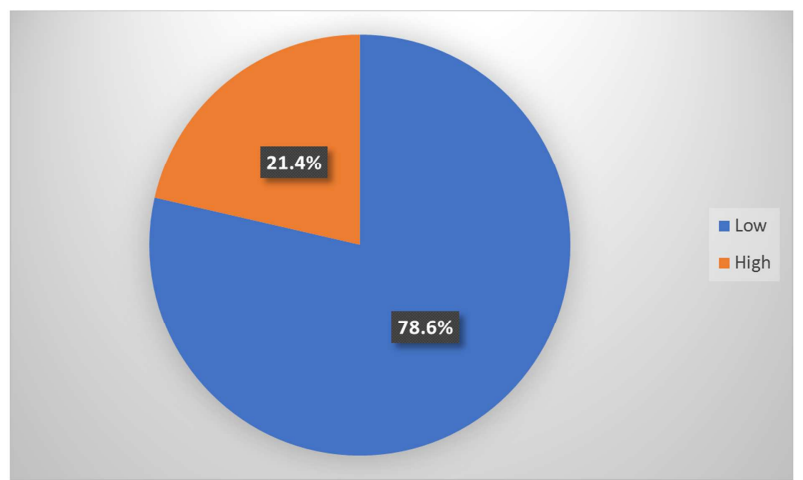

Figure 2. Level of knowledge of teachers on Autism Spectrum Disorder. 
Table 3. Knowledge of ASD questionnaire failed by $>50 \%$ of respondents.

\begin{tabular}{lll}
\hline Question & Correct Response & \% correct (95\% CI) \\
\hline 1. Autistic children present with language delay & True & $75.24(68.8-80.9)$ \\
2. Autism is curable & False & $43.33(36.5-50.3)$ \\
3. Autism is caused by poor parenting & False & $34.29(27.9-41.1)$ \\
4. Autism is a psychological problem & False & $32.38(26.1-39.2)$ \\
5. Diet can make a difference in autism & False & $30.48(24.3-37.2)$ \\
6. Autism presents in repetitive behaviour & True & $59.52(52.6-66.2)$ \\
7. Autism occurs in less than 10\% of the population & True & $45.24(38.4-52.2)$ \\
8. Autistic children are unable to pursue higher education & False & $49.05(42.1-56.0)$ \\
9. Autistic children do not want friends & True & $30.95(24.8-37.7)$ \\
10. Autistic children do not show social attachments & True & $48.57(41.6-55.5)$ \\
11. An autistic child may avoid making eye contact & True & $35.24(28.8-42.1)$ \\
12. Autistic children should receive special education & True & $63.81(56.9-70.3)$ \\
13. Autistic children are deliberately negativistic & False & $37.14(30.6-44.1)$ \\
14. Rich parents are likely to have autistic children & False & $35.71(29.2-42.6)$ \\
15. Autistic children do not show affection & True & $33.81(27.4-40.6)$ \\
\hline
\end{tabular}

Note: CI- confidence interval

\subsection{Attitudes and Perceptions Towards Care and Education of Children with ASD}

Generally, the participants shared positive attitudes and perceptions illustrated by their strong opinions favoring improving educational opportunities for children with autism. The results of the categorization of the attitudes and perception showed that the majority, 183 (87.1\%) shared positive attitudes and perceptions towards improved education for children with ASD whereas the remaining 27 $(12.9 \%)$ shared a poor attitude towards improved education for children with ASD (figure 3).
The average score of participants in this domain was 3.71 $(\mathrm{SD}=0.47)$. More than half of preschool teachers agreed to the integration of children with special needs into mainstream schools, as well as preschools allowing parents with such children in the classroom. Between $70-80 \%$ of teachers also expressed strong opinions on the government allocating more resources for providing needed services for special needs children and also on preschools having therapists and specially-trained teachers to provide therapies and treatment to children with special needs who are enrolled in these preschools as shown in Table 6.

Table 4. Attitudes and Perceptions towards care and education of children with Autism Spectrum Disorder.

\begin{tabular}{|c|c|c|c|c|c|c|}
\hline Statement & Average score & 1 & 2 & 3 & 4 & 5 \\
\hline 1. Special-needs children should be integrated into mainstream schools & 3.85 & $8.10 \%$ & $7.62 \%$ & $12.86 \%$ & $33.81 \%$ & $37.62 \%$ \\
\hline $\begin{array}{l}\text { 2. Preschools should allow special-needs children to attend classes while they await } \\
\text { placement }\end{array}$ & 3.88 & $4.29 \%$ & $5.71 \%$ & $16.19 \%$ & $45.71 \%$ & $28.10 \%$ \\
\hline 3. Preschools should allow the presence of parents in class & 3.69 & $8.57 \%$ & $13.33 \%$ & $16.19 \%$ & $24.29 \%$ & $37.62 \%$ \\
\hline 4. Preschools should have teachers and therapists to provide special education & 4.07 & $1.43 \%$ & $2.86 \%$ & $15.71 \%$ & $47.14 \%$ & $32.86 \%$ \\
\hline $\begin{array}{l}\text { 5. Government funding should be available to facilitate staff employment to meet } \\
\text { the needs of these children }\end{array}$ & 4.1 & $0.43 \%$ & $1.90 \%$ & $22.86 \%$ & $36.67 \%$ & $38.10 \%$ \\
\hline 6. Parents should help bear the cost of services within the preschool & 2.07 & $24.76 \%$ & $50.48 \%$ & $19.05 \%$ & $4.29 \%$ & $1.43 \%$ \\
\hline 7. There is adequate provision of services of special-needs children in Ghana & 3.71 & $5.74 \%$ & $6.70 \%$ & $23.44 \%$ & $38.76 \%$ & $25.36 \%$ \\
\hline $\begin{array}{l}\text { 8. The government should allocate more resources for the provision of services for } \\
\text { children with special needs }\end{array}$ & 4.03 & $1.43 \%$ & $1.90 \%$ & $17.62 \%$ & $50.00 \%$ & $29.05 \%$ \\
\hline $\begin{array}{l}\text { 9. Insurance policies should be amended to include coverage for developmental } \\
\text { disorders }\end{array}$ & 3.99 & $1.43 \%$ & $2.86 \%$ & $24.76 \%$ & $37.62 \%$ & $33.33 \%$ \\
\hline
\end{tabular}

Note: $1=$ strongly disagree, $2=$ disagree, $3=$ Neutral, $4=$ agree, $5=$ strongly agree

\subsection{Influence of Knowledge on Attitudes and Perceptions}

A linear regression analysis of the strength of association revealed that the level of knowledge of participants significantly influenced the attitudes and perceptions of preschool teachers. The test revealed that the level of knowledge of participants was significantly associated with the attitudes and perceptions of participants towards educating and caring for children with autism $(\mathrm{p}=0.042)$. After adjusting for the effect of the socio-demographic characteristics that could be potential confounders on the mean score of attitudes and perceptions, it was still observed that the knowledge level of participants was significantly associated with the attitudes and perceptions of participants $(\mathrm{p}=0.047)$. Table 5 shows this relationship. 
Table 5. The effect of knowledge on attitudes and perceptions of pre-school teachers towards the care and education of children with autism.

\begin{tabular}{lllll}
\hline \multirow{2}{*}{ Characteristics } & Unadjusted & & Adjusted $^{\mathbf{1}}$ \\
\cline { 2 - 5 } & Mean difference (95\%CI) & Unadjusted P-value & Adjusted Mean difference (95\%CI) & Adjusted P-value \\
\hline $\begin{array}{l}\text { Level of Knowledge } \\
\text { Total composite score }\end{array}$ & $-0.023(-0.045,-0.001)$ & & $-0.023(-0.045,-0.00)$ & 0.047 \\
\hline
\end{tabular}

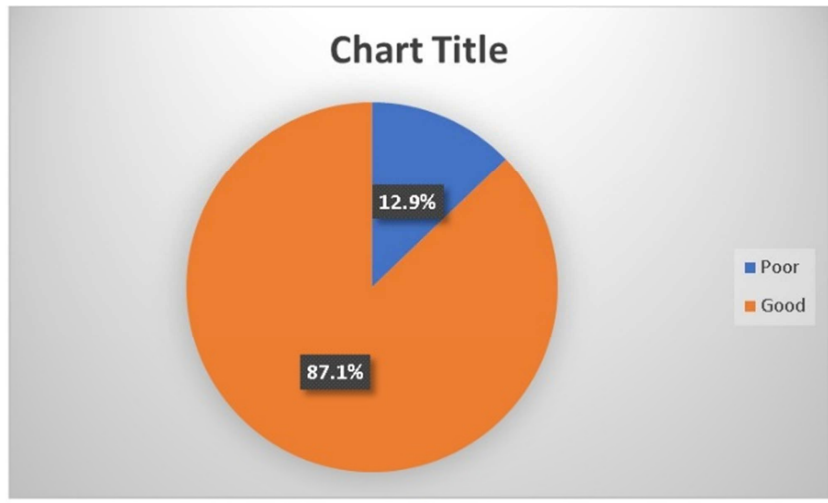

Figure 3. Attitudes and perception towards children with autism.

1 Estimates were adjusted for the effect of background characteristics on the attitudes and perceptions of participants.
The linear regression model of the factors associated with knowledge of ASD showed that training in early childhood development was significantly associated with knowledge of ASD (coef $=-0.57, p=0.01$ ). The results further showed that training in special needs also presented a strong association with knowledge of ASD and the association was statistically significant (coef $=-0.67, \mathrm{p}=0.003$ ). Other variables such as age, school type, sex of respondents, among others were not significantly associated with knowledge of ASD ( $>0.05)$. In the adjusted model, no variable presented a significant association with knowledge of ASD. Despite being significantly associated with knowledge of ASD in the crude model, having training in early childhood development and having training in special needs were not significantly associated with knowledge of ASD in the adjusted model (Table 6).

\subsection{Factors Associated with Knowledge of Autism}

Table 6. Linear regression model of Factors associated with knowledge of autism.

\begin{tabular}{|c|c|c|c|c|}
\hline \multirow{2}{*}{ Characteristics } & \multicolumn{2}{|l|}{ Unadjusted } & \multicolumn{2}{|l|}{ Adjusted $^{1}$} \\
\hline & Coefficient $(95 \% \mathrm{CI})$ & Unadjusted P-value & Coefficient $(95 \% \mathrm{CI})$ & Adjusted P-value \\
\hline School type & $0.02(-0.52,0.57)$ & 0.92 & $0.01(-0.58,0.62)$ & 0.96 \\
\hline Sex & $0.17(-0.28,0.63)$ & 0.45 & $0.15(-0.32,0.61)$ & 0.54 \\
\hline Marital status & $0.01(-0.43,0.46)$ & 0.96 & $-0.34(-0.97,0.29)$ & 0.29 \\
\hline Child bearing & $-0.19(-0.64,0.25)$ & 0.39 & $-0.17(-0.85,0.50)$ & 0.62 \\
\hline Level of education & $-0.07(-0.39,0.25)$ & 0.66 & $-0.03(-0.44,0.39)$ & 0.91 \\
\hline Teaching experience & $-0.001(-0.04,0.03)$ & 0.97 & $0.03(-0.03,0.10)$ & 0.34 \\
\hline \multicolumn{5}{|l|}{ Training in childhood development } \\
\hline Yes & (Ref) & $0.01 * *$ & 1.00 (Ref) & 0.26 \\
\hline No & $-0.57(-1.02,-0.12)$ & & $0.96(-0.70,2.63)$ & \\
\hline \multicolumn{5}{|l|}{ Training in special needs } \\
\hline Yes & 1.00 (Ref) & $0.003 * *$ & 1.00 (Ref) & 0.06 \\
\hline No & $-0.67,(-1.13,-0.23)$ & & $-1.61(-3.29,0.27)$ & \\
\hline Experience with special needs child & $-0.001(-0.27,0.27)$ & 0.99 & $-0.01(-0.29,0.27)$ & 0.93 \\
\hline
\end{tabular}

\subsection{Factors Associated with Attitudes and Perceptions Towards Autism}

The results of the linear regression of the factors associated with the attitude and perception towards children with autism showed that the teaching experience of the respondents had a statistically significant association with their attitudes and perceptions (coef $=0.15, p=0.007$ ) in the crude model. Their experience with a child with special needs also presented a statistically significant association with their attitude and perceptions (coef $=0.94, p=0.01$ ). Even though experience with special needs children was significantly associated with attitudes and perceptions in the crude analysis, it was not significantly associated with attitudes and perceptions in the adjusted model. The only variable that presented a significant association with attitudes and perceptions in the adjusted model was teaching experience $(\operatorname{coef}=0.20, \mathrm{p}=0.03)$. All other variables were not significantly associated with attitudes and perceptions in both the adjusted and crude model (table 7). 
Table 7. Linear regression model of Factors associated with attitude and perception towards autism.

\begin{tabular}{lllll}
\hline \multirow{2}{*}{ Characteristics } & Unadjusted & & Adjusted $^{\mathbf{1}}$ \\
\cline { 2 - 5 } & Coefficient (95\%CI) & Unadjusted P-value & Coefficient (95\%CI) & Adjusted P-value \\
\hline School type & $-0.16(-1.6,1.30)$ & 0.83 & $-0.09(-1.69,1.49)$ & 0.91 \\
Age of respondent & $0.05(-0.01,0.11)$ & 0.09 & $-0.02(0.13,0.10)$ & 0.79 \\
Sex & $-0.17(-1.38,1.04)$ & 0.78 & $0.02(-1.21,1.25)$ & 0.97 \\
Marital status & $-0.40(-1.60,0.80)$ & 0.52 & $0.84(-0.81,2.49)$ & 0.32 \\
Child bearing & $1.14(-0.05,2.33)$ & 0.06 & $0.76(-1.01,2.53)$ & 0.40 \\
Level of education & $-0.32(-1.18,0.54)$ & 0.47 & $-0.96(-2.05,0.12)$ & 0.08 \\
Teaching experience & $0.15(0.04,0.25)$ & $0.007^{* *}$ & $0.20(0.01,0.39)$ & $0.03^{*}$ \\
Training in childhood development & $0.71(-0.51,1.92)$ & 0.25 & $0.04(-4.35,4.42)$ & 0.98 \\
Training in special needs & $0.7(-0.52,1.92)$ & 0.26 & $0.61(-3.84,5.06)$ & 0.79 \\
Experience with special needs child & $0.94(0.22,1.66)$ & $0.01 * *$ & $0.72(-0.02,1.47)$ & 0.05 \\
\hline
\end{tabular}

\section{Discussion}

Findings from this study revealed that majority of the participants $(78.6 \%)$ had a low level of knowledge of child autism with the majority of them unable to answer accurately to half of the items in the domain of Autism Spectrum Disorder. Findings from this study corroborate findings in Africa by establishing the low awareness of child autism knowledge among the general population including preschool teachers; a population that plays a vital role in the early detection and management of autism spectrum disorder [10, $28,29]$. Quite similarly, findings from a study conducted in China reported low levels of adequate knowledge on Autism Spectrum Disorder [21]. It is however imperative that the people that work closest to these children in their tender age have adequate knowledge of the condition to enable them to detect it in its prime stage.

This study further revealed that slightly less than half of respondents had adequate knowledge on typical childhood development which contrasts findings from previous research where the majority of participants had adequate knowledge in typical childhood development [21]. This is quite problematic and conflicting because the study population are preschool teachers and majority indicated they had received training in early childhood development. It is therefore expected that they would have adequate knowledge in the development of the children they are dealing with. This perhaps could be attributed to the high percentage of the participants who reported having a WASSCE/SSCE certificate since the results indicated that level of education was significantly associated with knowledge in typical childhood development $(p<0.01)$. This was also confirmed by another study that higher levels of education were significantly associated with higher knowledge in typical childhood development [30]. Most participants identified child autism as a psychological problem which is similar to what another study found [22].

This study brought to light the attitudes and perceptions that preschool teachers in the mainstream preschools in Lekma hold towards the care and education of children with autism. The results showed that majority $(87.1 \%)$ of the participants supported the integration of children with special needs into mainstream schools. This is similar to findings by another study about preschool teachers supporting the integration of special-needs children into mainstream classrooms [27]. Participants agreed that government funding should be readily available to provide staff employment services for children with special needs. These findings however contrast findings of another study where participants were neutral in their opinions regarding the integration of special-needs children into mainstream schools [31]. This could be a result of the slight differences in the level of knowledge of participants regarding ASD in the two studies. Participants however showed agreement to the presence of parents of children with special needs in the classroom and this was also affirmed by the previous study [32].

Findings of the study showed that participants who did not have training in early child development presented a -0.57 decrease in knowledge of autism and those who did not have any training in special needs presented a -0.67 decrease in knowledge of autism. These findings are similar to findings by other studies that training in special needs and training in early child development influences knowledge on autism [33, 34]. The study found that age, sex, marital status, working experience, among others were not significantly associated with the level of knowledge of autism and this finding is similar to findings by another study [10].

The findings of the study revealed that participants' teaching experience and previous encounters with autistic children presented a 0.15 and 0.94 increment respectively in their attitude and perception towards education for children with autism. This is similar to findings by other studies [29, 35]. Despite being reported by other studies that sex, school type, and educational level of participants were significantly associated with knowledge on ASD [21,36], findings from this study did not show any significant association between many of the demographic characteristics (school type, sex, marital status, childbearing, educational level, etc.) and the knowledge on ASD as well as attitude and perceptions towards ASD. 
Participants had significantly low levels of knowledge on autism and child development. However, they presented a high positive attitude towards education for children with autism. Also, total knowledge score and attitude and perception were significantly associated. This discrepancy could be well explained by a report that, the attitudes that most individuals exhibit towards various disorders are a result of assumptions rather than knowledge or evidence [37] This implies that their positive attitude and perception towards education for children with autism was mainly based on their assumptions and not on their knowledge. Similarly, another study found significant associations between knowledge and stigma change as well as knowledge and attitudes $[16,38]$. In a paper commissioned by the Education for all Global Monitoring (EFA) Report, on access to education for students with autism in Ghana, it was concluded that, for autistic children to have successful education, there is the need for teachers to have an accurate understanding of the disorder as well as its unique characteristics [39]. This, as stated is necessary to achieve inclusive education for autistic children in Ghana.

\section{Limitations and Strengths of the Study}

The key strength of this study can be attributed to the fact that it is one of the few quantitative studies to assess the knowledge of ASD among preschool teachers in the Greater Accra Region and Ghana at large.

One limitation lies within the generalizability of the results due to the limited number of participants successfully reached, which is accounted for by the limited proportion of consenting participants. Another possible limitation would be the method of purposive sampling used in the multi-stage sampling which may have introduced selection bias.

\section{Conclusion}

The knowledge of ASD among preschool teachers found in this study was relatively low. Given the important role knowledge plays in ASD, successive measures must be taken to enhance teachers' knowledge of ASD. In determining the attitudes and perceptions that respondents held towards the disorder, it was observed that preschool teachers held fairly positive attitudes and perceptions towards care for autistic children. Findings also revealed that respondents were in support of the integration of children with special needs into mainstream preschools and also shared strong opinions that government needs to provide adequate services to help make this integration possible.

\section{List of Abbreviation}

ASD- Autism Spectrum Disorder

\section{Availability of Data}

The datasets used and/or analyzed during the current study are available from the corresponding author on reasonable request

\section{Competing Interests}

The authors declare that they have no competing interests.

\section{Funding}

The authors did not receive any funding for the present study. The study was therefore self-funded by the authors.

\section{References}

[1] American Psychiatric Association. Neurodevelopmental Disorders: DSM-5® Selections. American Psychiatric Pub; 2015 Aug 27.

[2] Inglese MD, Elder JH. Caring for children with autism spectrum disorder, part I: Prevalence, etiology, and core features. Journal of pediatric nursing. 2009 Feb 1; 24 (1): 41-8. https://doi.org/10.1016/j.pedn.2007.12.006.

[3] McGinnity Á, Meltzer H, Ford T, Goodman R. Mental health of children and young people in Great Britain, 2004. Green H, editor. Basingstoke: Palgrave Macmillan; 2005 Sep. https://doi.org/10.1037/e557702010-001

[4] Tonkin BL, Ogilvie BD, Greenwood SA, Law MC, Anaby DR. The participation of children and youth with disabilities in activities outside of school: A scoping review: Étude de délimitation de l'étendue de la participation des enfants et des jeunes handicapés à des activités en dehors du contexte scolaire. Canadian Journal of Occupational Therapy. 2014 Oct; $\quad 81 \quad$ (4): $\quad 226-36$. https://doi.org/10.1177/0008417414550998.

[5] Mazurek MO, Kanne SM, Wodka EL. Physical aggression in children and adolescents with autism spectrum disorders. Research in Autism Spectrum Disorders. 2013 Mar 1; 7 (3): 455-65. https://doi.org/10.1016/j.rasd.2012.11.004.

[6] See CM. The use of music and movement therapy to modify behaviour of children with autism. Pertanika Journal of Social Sciences \& Humanities. 2012 Dec 1; 20 (4).

[7] Lai MC, Lombardo MV, Pasco G, Ruigrok AN, Wheelwright SJ, Sadek SA, Chakrabarti B, Baron-Cohen S, MRC AIMS Consortium. A behavioral comparison of male and female adults with high functioning autism spectrum conditions. PloS

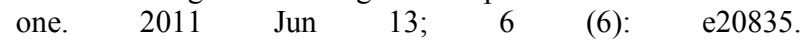
https://doi.org/10.1371/journal.pone.0020835.

[8] Ballentine F. Sensory experiences of children with an autism spectrum disorder and nursing interventions for over stimulation. Etd. Fcla. Edu, (2011). http://etd.fcla.edu/CF/CFH0004063/Ballentine_Felicia_M_20 1108 BSN.pdf. Accessed $14^{\text {th }}$ June, 2019.

[9] Maenner MJ, Shaw KA, Baio J. Prevalence of autism spectrum disorder among children aged 8 years - autism and developmental disabilities monitoring network, 11 sites, United States, 2016. MMWR Surveillance Summaries. 2020 Mar 27; 69 (4): 1. 
[10] Sampson WG, Sandra AE. Comparative study on knowledge about autism spectrum disorder among paediatric and psychiatric nurses in Public Hospitals in Kumasi, Ghana. Clinical practice and epidemiology in mental health: CP \& EMH. 2018; $14: 29$. https://doi.org/10.2174/1745017901814010099.

[11] Dillenburger K, Jordan JA, McKerr L, Lloyd K, Schubotz D. Autism awareness in children and young people: Surveys of two populations. Journal of Intellectual Disability Research. 2017 Aug; 61 (8): 766-77. https://doi.org/10.1111/jir.12389.

[12] Barnard L, Muldoon K, Hasan R, O'Brien G, Stewart M. Profiling executive dysfunction in adults with autism and comorbid learning disability. Autism. 2008 Mar; 12 (2): 12541. https://doi.org/10.1177/1362361307088486.

[13] Elsabbagh M, Divan G, Koh YJ, Kim YS, Kauchali S, Marcín C, Montiel-Nava C, Patel V, Paula CS, Wang C, Yasamy MT. Global prevalence of autism and other pervasive developmental disorders. Autism research. 2012 Jun; 5 (3): 160-79. https://doi.org/10.1002/aur.239.

[14] Ruparelia K, Abubakar A, Badoe E, Bakare M, Visser K, Chugani DC, Chugani HT, Donald KA, Wilmshurst JM, Shih A, Skuse D. Autism spectrum disorders in Africa: Current challenges in identification, assessment, and treatment: A report on the International child neurology association meeting on ASD in Africa, Ghana, April 3-5, 2014. Journal of child neurology. 2016 Jul; 31 (8): 1018-26. https://doi.org/10.1177/0883073816635748.

[15] Makrygianni MK, Gena A, Katoudi S, Galanis P. The effectiveness of applied behavior analytic interventions for children with Autism Spectrum Disorder: A meta-analytic study. Research in Autism Spectrum Disorders. 2018 Jul 1; 51: 18-31. https://doi.org/10.1016/j.rasd.2018.03.006.

[16] Dolah J, Yahaya WA, Chong TS. A preliminary investigation: Potential of interactive multimedia learning awareness (IMLA) in enhancing awareness of autistic characteristics among parents and society in Malaysia. Electronic Journal of Computer Science and Information Technology. $2011 \mathrm{Jul}$ 7; 3 (1).

[17] Obeid R, Daou N, DeNigris D, Shane-Simpson C, Brooks PJ, Gillespie-Lynch K. A cross-cultural comparison of knowledge and stigma associated with autism spectrum disorder among college students in Lebanon and the United States. Journal of autism and developmental disorders. 2015 Nov 1; 45 (11): 3520-36. https://doi.org/10.1007/s10803-015-2499-1.

[18] Kang-Yi CD, Grinker RR, Beidas R, Agha A, Russell R, Shah $\mathrm{SB}$, Shea K, Mandell DS. Influence of community-level cultural beliefs about autism on families' and professionals' care for children. Transcultural psychiatry. 2018 Oct; 55 (5): 623-47. https://doi.org/10.1177/1363461518779831.

[19] Ooi KL, Ong YS, Jacob SA, Khan TM. A meta-synthesis on parenting a child with autism. Neuropsychiatric disease and treatment. 2016 Apr 5. https://doi.org/10.2147/NDT.S100634.

[20] Arif MM, Niazy A, Hassan B, Ahmed F. Awareness of autism in primary school teachers. Autism Research and Treatment. 2013 Nov 30; 2013.

[21] Liu Y, Li J, Zheng Q, Zaroff CM, Hall BJ, Li X, Hao Y. Knowledge, attitudes, and perceptions of autism spectrum disorder in a stratified sampling of preschool teachers in China. BMC psychiatry. 2016 Dec 1; 16 (1): 142. https://doi.org/10.1186/s12888-016-0845-2.

[22] Surmen A, Hidiroglu S, Usta HH, Awiwi M, Oguz AS, Karavus M, Karavus A. A study exploring knowledge, attitudes and behaviours towards autism among adults applying to a Family Health Center in Istanbul. Northern clinics of Istanbul. 2015; 2 (1): 13. https://doi.org/10.14744/nci.2015.83723.

[23] Bakare MO, Munir KM. Autism spectrum disorders (ASD) in Africa: a perspective. African journal of psychiatry. 2011; 14 (3): $208-10$. https://doi.org/http://dx.doi.org/10.4314/ajpsy.v14i3.3.

[24] Dillenburger K, McKerr L, Jordan JA, Keenan M. Staff training in autism: the one-eyed wo/man.... International journal of environmental research and public health. $2016 \mathrm{Jul}$; 13 (7): 716. https://doi.org/10.3390/ijerph13070716.

[25] Harrison AJ, Slane MM, Hoang L, Campbell JM. An international review of autism knowledge assessment measures. Autism. 2017 Apr; 21 (3): 262-75. https://doi.org/10.1177/1362361316638786.

[26] Ledzokuku Krowor Municipal Assembly (2019). Ledzokuku Krowor Municipal Assembly. https://www2.statsghana.gov.gh/docfiles/2010_District_Rep ort/Greater\%20Accra/LEKMA.pdf. Accesse $\bar{d} 13^{\text {th }}$ April 2019.

[27] Lian WB, Ying SH, Tean SC, Lin DC, Lian YC, Yun HL. Pre-school teachers' knowledge, attitudes and practices on childhood developmental and behavioural disorders in Singapore. Journal of paediatrics and child health. 2008 Apr; 44 (4): 187-94. https://doi.org/10.1111/j.14401754.2007.01231.x.

[28] Bakare MO, Ebigbo PO, Agomoh AO, Eaton J, Onyeama GM, Okonkwo KO, Onwukwe JU, Igwe MN, Orovwigho AO, Aguocha CM. Knowledge about childhood autism and opinion among healthcare workers on availability of facilities and law caring for the needs and rights of children with childhood autism and other developmental disorders in Nigeria. BMC pediatrics. 2009 Dec 1; 9 (1): 12. https://doi.org/10.1186/1471-2431-9-12.

[29] Igwe MN, Ahanotu AC, Bakare MO, Achor JU, Igwe C. Assessment of knowledge about childhood autism among paediatric and psychiatric nurses in Ebonyi state, Nigeria. Child and adolescent psychiatry and mental health. $2011 \mathrm{Dec}$ 1; 5 (1): 1. https://doi.org/10.1186/1753-2000-5-1.

[30] Alharbi KA, Alharbi AA, Al-Thunayyan FS, Alsuhaibani KA, Alsalameh NS, Alhomaid MH, Albahouth IS, Hamid PF. School's Teachers Knowledge About Autism in AlBadayacity, Al-Qassim Region, Kingdom of Saudi Arabia. Materia Socio-Medica. 2019 Mar; 31 (1): 4. https://doi.org/10.5455/msm.2019.31.4-9.

[31] Jensen CM, Martens CS, Nikolajsen ND, Skytt Gregersen T, Heckmann Marx N, Goldberg Frederiksen M, Hansen MS. What do the general population know, believe and feel about individuals with autism and schizophrenia: Results from a comparative survey in Denmark. Autism. 2016 May; 20 (4): 496-508. https://doi.org/10.1177/1362361315593068.

[32] Humphrey N, Symes W. Inclusive education for pupils with autistic spectrum disorders in secondary mainstream schools: teacher attitudes, experience and knowledge. International Journal of Inclusive Education. 2013 Jan 1; 17 (1): 32-46. https://doi.org/10.1080/13603116.2011.580462. 
[33] Barned NE, Knapp NF, Neuharth-Pritchett S. Knowledge and attitudes of early childhood preservice teachers regarding the inclusion of children with autism spectrum disorder. Journal of Early Childhood Teacher Education. 2011 Oct 1; 32 (4): 302-21.

[34] Hadi MS, Kassim NM. Kindergartens Teachers Early Detection Knowledge about Autism Spectrum Disorder in Babylon Province. International Journal of Psychosocial Rehabilitation. 2020; 24 (04).

[35] Atun-Einy O, Ben-Sasson A. Pediatric allied healthcare professionals' knowledge and self-efficacy regarding ASD. Research in Autism Spectrum Disorders. 2018 Mar 1; 47: 1-3. https://doi.org/10.1016/j.rasd.2017.12.001.

[36] Anwar MS, Tahir M, Nusrat K, Khan MR. Knowledge, Awareness, and Perceptions Regarding Autism Among Parents in Karachi, Pakistan. Cureus. 2018 Sep; 10 (9). https://doi.org/10.7759/cureus.3299.
[37] Durand-Zaleski I, Scott J, Rouillon F, Leboyer M. A first national survey of knowledge, attitudes and behaviours towards schizophrenia, bipolar disorders and autism in France. BMC psychiatry. 2012 Dec; 12 (1): 1-8. https://doi.org/10.1186/1471-244X-12-128.

[38] Papadopoulos C. Autism stigma and the role of ethnicity and culture. Network Autism. 2016 Oct 26.

[39] Anthony JH. Access to education for students with autism in Ghana: Implications for EFA. Background paper for EFA Global Monitoring Report. 2010.

[40] United Nations Development Programme, Ghana (UNDP) (2020). Sustainable development goals. http://www.gh.undp.org. Accessed 24 June, 2020. 